\title{
[Note］嗍珪酸ガラスの直流伝導および低周波誘電 吸収における硼酸異常現象の欠如
}

\author{
熊田虔・並河洋・中島達二・宗像元介
}

(電 気 試 験 所)

\section{Lack of Boronanomaly in D.C. Conduction and Low Frequency Dielectric Absorption in a Series of Alkali Borosilicate Glasses}

By

Ken KUMATA, Hiroshi NAMIKAWA, Tatsuji NAKAJIMA

and Motosuke MUNAKATA

(Electrotechnical Laboratory, Tokyo)

嗍酸異常とは，硼酸を含むガラス系において，熱膨 膨, 密度, 耐水性等の物理的, 化学的性質と組成との関 係が，それぞれの性質に固有の硼酸含量のところで，極 值または屈曲点を生じる現象である ${ }^{1)}$.

電気的性質の硼酸異常現象に関しては Stevels の研究 がある (図-1 $\left.1^{2)}\right) 、 \mathrm{Na}_{2} \mathrm{O}\left(\mathrm{Li}_{2} \mathrm{O}\right)-\mathrm{SiO}_{2}-\mathrm{B}_{2} \mathrm{O}_{3}$ 系ガラス の $20^{\circ} \mathrm{C}, 1.5 \mathrm{Mc}$ における $\tan \delta$ は $\mathrm{Na}_{2} \mathrm{O}\left(\mathrm{Li}_{2} \mathrm{O}\right)$ が 16 mol\% において極小になることが報告されている. Stevels はその原因として，この誘電損失は $\mathrm{Na}^{+}\left(\mathrm{Li}^{+}\right)$ のイオン移動損失 (migration loss) によるもので,

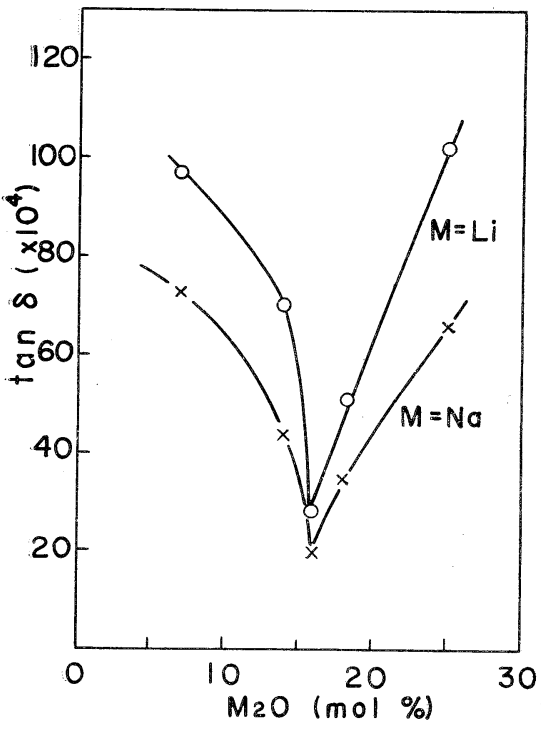

Fig. 1. Change of $\tan \delta$ with $\mathrm{Na}_{2} \mathrm{O}\left(\mathrm{Li}_{2} \mathrm{O}\right)$ content in the system $\mathrm{M}_{2} \mathrm{O}-\mathrm{B}_{2} \mathrm{O}_{3}$ $\mathrm{SiO}_{2}(\mathrm{M}=\mathrm{Na}$ and $\mathrm{Li})$ at the frequency of $1.5 \mathrm{Mc}$ and $20^{\circ} \mathrm{C}\left(\right.$ Stevels $\left.^{2)}\right)$.
$\mathrm{Na}_{2} \mathrm{O}\left(\mathrm{Li}_{2} \mathrm{O}\right)$ が $16 \mathrm{~mol} \%$ でガラスの網目構造が最も密 になって $\mathrm{Na}^{+}\left(\mathrm{Li}^{+}\right)$の易動度が極小になることを挙げ ている.しかし，一周波数，一温度点だけの測定では， 誘電損失の性格を断定するには不十分である.さらに， もし，イオン移動損失に極小が現われるならば，これと 密接な関係にある直流導電率 ${ }^{3}$ にも極小があると予想さ れるが，それに関しては報告されていない。

本報告は硼珪酸ガラスの直流導電率と広範囲の周波数 域 $\left(10^{-4} \sim 10^{6} \mathrm{c} / \mathrm{s}\right)$ における誘電特性を広い温度域で測 定して, 観察された低周波誘電吸収の性格を検討した後 に，これらの電気的性質に硼酸異常が現われないことを 確かめたものである.

実験は分相域をはずした， $x \mathrm{Na}_{2} \mathrm{O}-(90-x) \mathrm{B}_{2} \mathrm{O}_{3}-$ $10 \mathrm{SiO}_{2}(\mathrm{~mol} \%)$ の Stevels と同じ組成を持った試料に ついて行なわれた. ガラスは熔融後, 転移温度附近から 炉内放冷して作られたが肉眼で見るかぎり分相は認めら れなかった。一方, 熱膨膨係数に関しては硼酸異常を示 すことが確認された（図-2). 電気測定は, 電極として 銀を蒸着した試料について行なわれた. 直流導電率测定 には振動容量型電位計を, 誘電特性 (誘電率, 誘電損 率) 測定には変成器 ブリッジ $\left(10^{6} \sim 30 \mathrm{c} / \mathrm{s}\right)$ と超低周波 ブリッジ $\left(10 \sim 10^{-1} \mathrm{c} / \mathrm{s}\right)$ とを用いた。 $10^{-2} \sim 10^{-4} \mathrm{c} / \mathrm{s}$ の 誘電損率は前記の導電率の測定時に観測される吸収電流 から，Hamon-中島 ${ }^{4)}$ の式を用いて算出した。

図-3には伝導損失の寄与を差し引いた誘電損率 $\left(\varepsilon^{\prime \prime}\right.$ $\left.=\varepsilon^{\prime} \cdot \tan \delta\right)$ 周波数特性の代表例 $\left(18 \mathrm{Na}_{2} \mathrm{O}-10 \mathrm{SiO}_{2}-\right.$ $72 \mathrm{~B}_{2} \mathrm{O}_{3}$ ) を示す. Stevels の測定の場合よりはるかに低 周波領域に，温度上昇にともなって高周波側に移動する 明瞭な誘電吸収を観察することができる，もし，ここに 観察された誘電吸収が $\mathrm{Na}^{+}$の移動損失によるものであ 


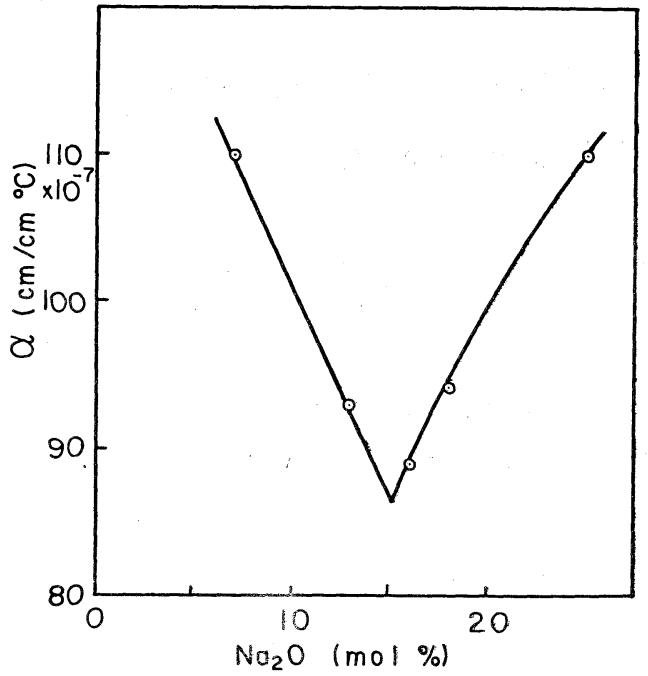

Fig. 2. Change of thermal expansion coefficient with $\mathrm{Na}_{2} \mathrm{O}$ content of $x \mathrm{Na}_{2} \mathrm{O}-(90-x)$ $\mathrm{B}_{2} \mathrm{O}_{3}-10 \mathrm{SiO}_{2}$ glasses.

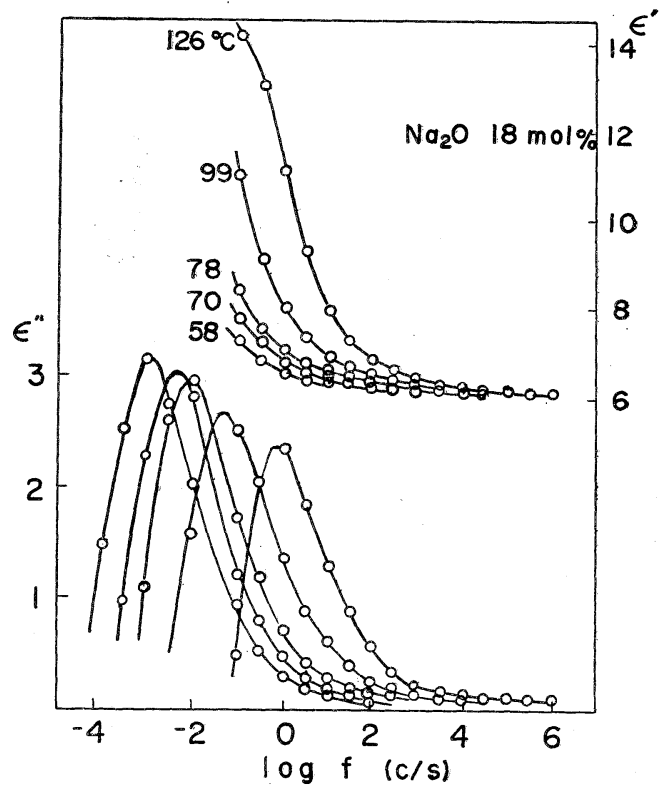

Fig. 3. Frequency dependence of $\varepsilon^{\prime}$ and $\varepsilon^{\prime \prime}$ of $18 \mathrm{Na}_{2} \mathrm{O}-72 \mathrm{~B}_{2} \mathrm{O}_{3}-10 \mathrm{SiO}_{2}$ glass.

れば，直流伝導との間に密接な関係があることが予想さ れる、たとえば, Taylor ${ }^{5}$ は多数のソーダ石灰珪酸塩ガ ラス, およびソーダ珪酸塩ガラスの低周波誘電吸収を測 定して，誘電緩和の活性化エネルギーが直流伝導のそれ と実験誤差の範囲内で等しいことから，観察された誘電 吸収が直流伝導の場合と同じくアルカリイオンの移動に よってもたらされたものであることを示唆した.さらに 中島は，これまでにいろいろな研究者によって行なわれ た含アルカリガラスの直流伝導と低周波誘電特性の多数 の実験結果を整理して，分相や結晶化を起していない普 通のガラスであれば，ガラスの組成に関係なく，導電率

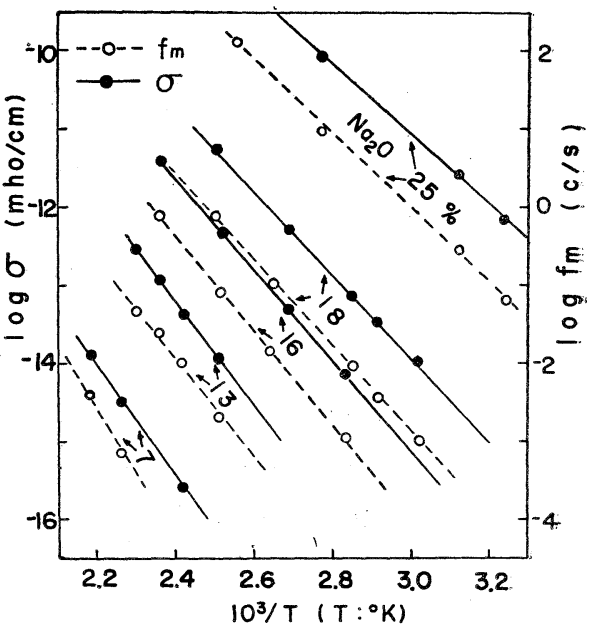

Fig. 4. Temperature dependence of $\sigma$ and $f_{m}$ $\begin{array}{llll}\text { of } x & \mathrm{Na}_{2} \mathrm{O}-(90-x) & \mathrm{B}_{2} \mathrm{O}_{3}-10 & \mathrm{SiO}_{2}\end{array}$ glasses.

と移動損失にもとづく誘電吸収との間に次の相関が成り゙ 立つことをしめしだ'.

$$
\sigma \div 2 \pi f_{m} \varepsilon_{0} \cdot \Delta \varepsilon
$$

ここで $\sigma$ は導電率 $(\mathrm{mho} / \mathrm{cm}), \varepsilon_{0}$ は真空の誘電率 $\left(0.0885 \times 10^{-12} \mathrm{~F} / \mathrm{cm}\right), f_{m}$ は吸収極大の周波数 $(\mathrm{c} / \mathrm{s})$ で あり $\Delta \varepsilon$ 绣電吸収の大きさで， $\log f \sim \varepsilon^{\prime \prime}$ 曲線と $\log$ $f$ 軸とに囲まれた面積から求められる。図-4 は, 本実 験にとりあげられた種々の $\mathrm{Na}_{2} \mathrm{O}$ 濃度を持つガラスの のおよび $f_{m}$ を絶対温度の逆数に対してプロットした ものである. 各々のガラスについての $\sigma$ と $f_{m}$ の傾斜 が平行であることから，誘電緩和の活性化エネルギーは 直流伝導のそれにほぼ等しいことがわかる.次に $2 \pi f_{m}$ • $\varepsilon_{0} \bullet \Delta \varepsilon$ を計算し，その詨数を $\sigma$ の対数に対してプロッ トしたのが 図-5 である.どの点もほぼ原点を通る $45^{\circ}$ の線上にのり， $\mathrm{Na}_{2} \mathrm{O}$ の濃度と測定温度によらず (1) 式 の関係が満たされていることがわかる.この結果 $x \mathrm{Na}_{2} \mathrm{O}$

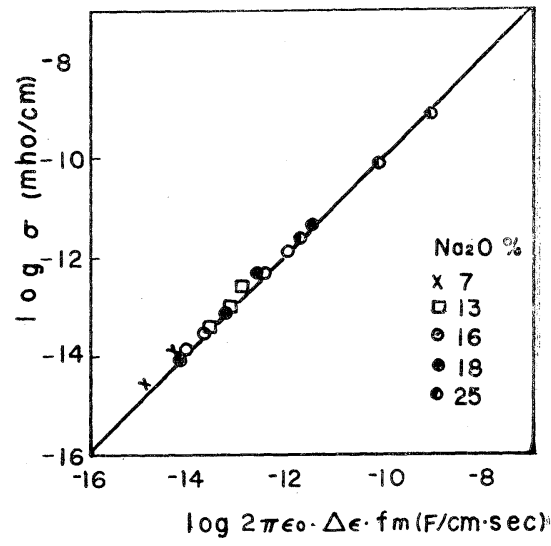

Fig. 5. Correlation between d.c. conductivity and dielectric absorption of $x \mathrm{Na}_{2} \mathrm{O}-$ $(90-x) \mathrm{B}_{2} \mathrm{O}_{3}-10 \mathrm{SiO}_{2}$ glasses. 


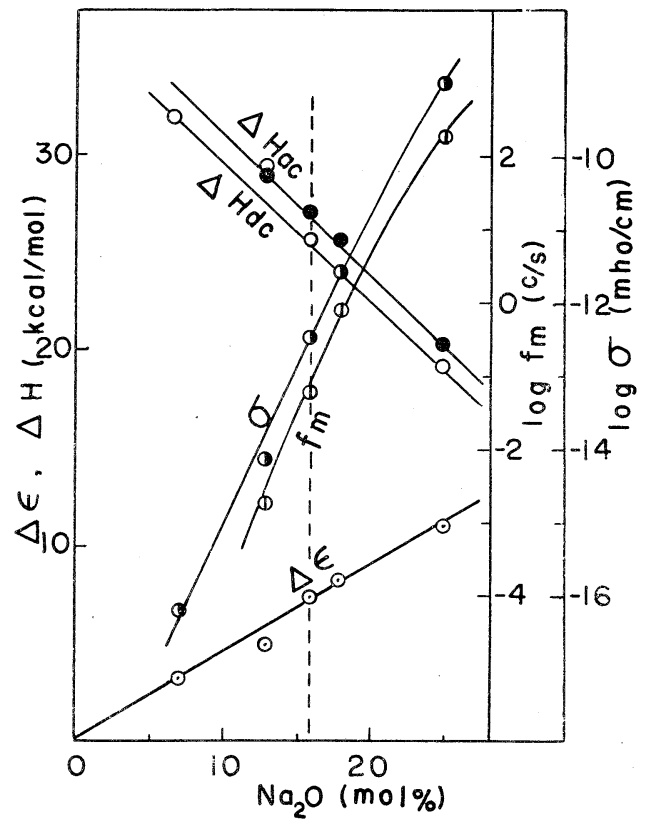

Fig. 6. Change of several electrical properties with $\mathrm{Na}_{2} \mathrm{O}$ content in $x \mathrm{Na}_{2} \mathrm{O}-(90-x)$ $\mathrm{B}_{2} \mathrm{O}_{3}-10 \mathrm{SiO}_{2}$ glasses.

一 (90-x) $\mathrm{B}_{2} \mathrm{O}_{3}-10 \mathrm{SiO}_{2}$ 系ガラスにおいて低周波領域 に観察される誘電吸収はいずれも, Stevels, Taylor ら のいらアルカリイオンの移動損失によるものであると結
論することができる.

図-6に $120^{\circ} \mathrm{C}$ におりる導電率 $(\sigma)$, 吸収極大の周波 数 $\left(f_{m}\right)$, 誘電吸収の大きさ $(\Delta \varepsilon)$, 直流伝導の 活性化工 ネルギー $\left(\Delta H_{d c}\right)$ および誘電緩和の活性化エネルギー $\left(\Delta H_{a c}\right)$ の $\mathrm{Na}_{2} \mathrm{O}$ 含量との関係を示す. $\mathrm{Na}_{2} \mathrm{O} 16 \mathrm{~mol}$ \%において, これらの電気量のいずれもが極大, 極小, 屈折などの特異な変化を示していない.すなわち, 直流 伝導および $\mathrm{Na}^{+}$によるイオン移動損失には Stevels が いうような硼酸異常が見られないと結論することができ る、そこで, Stevels の実験結果が正しいとすれば，高 周波域で存在するガラス網目の変形損失 (deformation loss）あるいは，イオンの共鳴吸収による振動損失 (vibration loss) を観測したものと考えられるが，こ れらについてはより高周波, さらに低温での測定がなさ れなければならない。

\section{文}

献

1）硼酸異常現像の定義については，たとえば 金沢孝文，七 ラミックス 2 [10] 802 (1967).

2) J.M. Stevels "The Electrical Properties of Glass" Article in Encyclopedia of Physics; XX, 380 BerlinGöttingen-Heiderberg : Spinger (1957).

3）中島達二, 第 12 回态用物理学関倸連合講演会予稿集 446 (1965).

4) 中島達二, 電気試験所彙報 24 [10] 755 (1960).

5) T.E. Taylor, J. Soc. Glass Tech. 43124 T (1959). (5/9/1968 受付)

[討 論]

\title{
アルミナの熱水反応における不純物の影響
}

\author{
小野修一郎・山口悟郎・柳田博明・清水紀夫（76 [7] 207-18（1968)）
}

下記の討論原稿は斎藤編集委員長宛に匿名希望で 投稿された ので, 投稿者との間に通信を交換した結果, 諸般の事情を考虑 して斎藤委員長名で発表した。

\section{斎藤進六氏の意見}

（1）「2.6. 結晶の成長」の節で「結晶面の成長の活 性化エネルギー」といら言葉が用いられていますが，他 に「結晶面の発達した」と六言葉も用いられていて, 面の方向（面の法線の方向）に成長する活性化エネルギ 一なのか，その面が大きくなるように成長する活性化エ ネルギーなのか，まぎらわしいよらに思います。ここで は反応温度による生成コランダムの晶癖変化から考え て, 前者の面の方向に成長する活性化エネルギーである と判断します.そうしますと, $c$ 面方向の成長はその活性 化エネルギーが, $r$ 面, $a$ 面方向の成長に比べて非常に低 いのにもかかわらず，一般に成長しにくいのはなぜかと
いら疑問がうかびます，この疑問に対する説明として， 界面エネルギーを考えることができると思います.すな わち, $c$ 面の界面エネルギ一が $r$ 面, $a$ 面に比べて低 く, 結晶全体の界面エネルギーを下げるために $c$ 面の割 合が $r$ 面， $a$ 面に比べて大きくなるように, つまり $r$ 面, $a$ 面方向に成長しやすいと考えることができます. $c$ 面があまり滑らかでなく $r$ 面， $n$ 面がいつも滑らかであ るのは,むしろ,この結果であると考えられます.この ように考えますと「不純物を添加した場合， $r$ 面の発達 するのが最も一般的で……c $c$ 面を発達させることはほと んどない」という事実に対して, 界面エネルギ一のより 大きな面に不純物イオンが選択的に吸着されて, 界面工 ネルギーを下げようとするため, その面の方向の成長が 阻害されると説明できます.この方が「高いエネルギー の活性化状態を必要とする面ほど不純物イオンの妨害を 受け易い」というよりも理解しやすいと思われます. 